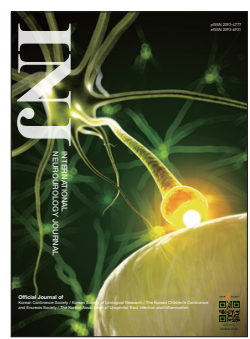

\title{
Antimuscarinic Agent Treatment Affecting Patient-Reported Outcomes in Overactive Bladder Syndrome With Depressive
}

\section{Symptoms}

\author{
Kyu Shik Kim, Hong Sang Moon \\ Department of Urology, Hanyang University College of Medicine, Seoul, Korea
}

Purpose: We investigated improvements in overactive bladder symptoms and depressive symptoms after solifenacin treatment in overactive bladder patients with or without depressive symptoms.

Methods: We performed a prospective study of patients who had been diagnosed with overactive bladder from July 2013 to June 2014. Based on the Beck Depression Inventory questionnaire, the test subjects were divided into group 1, without depressive symptoms (0-9 points), and group 2, with depressive symptoms (10 or more points). The patients were administered 5 mg of solifenacin for 3 months. The following outcomes were analyzed at the first visit, 4 weeks, and 12 weeks: the overactive bladder symptom score (OABSS), International Prostate Symptom Score (IPSS), patients' perceptions of their bladder condition, and the Beck Depression Inventory.

Results: A total of 72 patients participated, and 52 patients completed the study. Most outcome measures showed improvements in both groups at weeks 4 and 12. Especially in group 2, the questionnaires showed significant improvements from baseline to week 12, indicating that solifenacin was effective at treating overactive bladder symptoms (group 1 vs. group 2: OABSS, $-2.67 \pm 0.80$ vs. $-3.00 \pm 0.77 ; \mathrm{P}<0.01$; IPSS-total, $-2.14 \pm 2.15$ vs. $-4.94 \pm 1.70 ; \mathrm{P}<0.01)$. Statistically significant decreases in the Beck Depression Inventory score from baseline to weeks 4 and 12 were observed in group 2 (group 1 vs. group 2: $1.43 \pm 0.74$ vs. $-2.68 \pm 4.05$ at week $4, \mathrm{P}<0.001 ; 0.10 \pm 3.37$ vs. $-5.52 \pm 5.82$ at week $12, \mathrm{P}<0.001)$.

Conclusions: In overactive bladder patients with depressive symptoms, solifenacin can help improve quality of life and depressive symptoms at the same time.

Keywords: Urinary Bladder, Overactive; Depression; Quality of Life

- Fund Support: This study received financial support from Astellas Pharm Korea, Inc.

- Research Ethics: This study was performed with the approval of the Institutional Review Board of the Hanyang University Guri Hospital (approval number: 2013-01-046), and informed consent was obtained from the patients.

- Conflict of Interest: No potential conflict of interest relevant to this article was reported.

\section{INTRODUCTION}

According to the definition of the International Continence Society, overactive bladder (OAB) includes symptoms of urinary urgency with or without incontinence, often combined with urinary frequency and/or nocturia without any underlying disease, infection, or condition [1]. OAB is diagnosed in every age group, with similar prevalence in men and women, and its

Corresponding author: Hong Sang Moon (iD http://orcid.org/0000-0003-2101-1019 Department of Urology, Hanyang University Guri Hospital, 153 Gyeongchun-ro, Guri 11923, Korea

E-mail: moonuro@hanyang.ac.kr / Tel: +82-31-560-2374 / Fax: +82-31-560-2377 Submitted: July 3, 2016 / Accepted: August 12, 2016 
prevalence increases with age. The prevalence of OAB symptoms has been reported to be approximately $16 \%-27 \%$ and $33 \%-43 \%$ for men and women aged $\geq 40$ years, respectively, in the United States [2]. The annual cost due to OAB in the United States in the community and institutions was estimated to be 12 billion United States dollars (USD) in 2000 and 65.9 billion USD in 2007, with total national costs expected to increase $25 \%$ by 2020 , as the population ages [3]. OAB patients have a lower quality of life (QoL)due to their symptoms because patients not only tend to isolate themselves from social activities and personal relationships, but also experience impacts in the psychological, professional, physical, and sexual realms [4]. These decreases in QoL have an influence on mental health, and OAB patients often complain about depressive symptoms and concerns about increasing stress. Resources from the EPIC (European Prospective Investigation into Cancer and Nutrition) study, a multinational population-based survey performed in Europe and Canada, showed that the frequency of depression was high in $\mathrm{OAB}$ patients and that depression had a strong relationship with $\mathrm{OAB}$ diagnosis, regardless of incontinence status [5].

Treatments for OAB include lifestyle modifications, behavioral therapy, medication, botulinum toxin injection, neuromodulation, and surgical interventions [6]. Among these treatments, medication is widely used because of its rapid effectiveness and noninvasive nature. Antimuscarinic drugs are an important first-line drug therapy for OAB [7].

The frequency of depression in the general population is $2 \%-15 \%$, and the lifetime prevalence of depression is $16.5 \%$. Depression is predicted to become the second highest source of disease burden by the year 2020 [8]. Some studies have reported a relationship between depression and $\mathrm{OAB}$, but little research has been performed regarding depressive symptoms in individuals with $\mathrm{OAB}$. We investigated improvements in $\mathrm{OAB}$ symptoms and depressive symptoms after solifenacin treatment in $\mathrm{OAB}$ patients with and without depressive symptoms.

\section{MATERIALS AND METHODS}

\section{Study Design}

This study was a prospective investigation conducted at a single institution, targeting outpatients with OAB from July 2013 to June 2014. This study was performed with the approval of the Institutional Review Board of the Hanyang University Guri Hospital (approval number: 2013-01-046), and informed consent was obtained from the patients.
This study included female patients older than 20 years who did not have a medical history of taking antimuscarinic agents in the past 6 months, had an overactive bladder symptom score (OABSS) questionnaire question 3 (urgency) score higher than 2 points with a total score of over 3 points, were willing to participate in the clinical study, and consented to completing the questionnaires and an informed consent form. The following groups of patients were excluded: (1) patients for whom antimuscarinic agents were contraindicated, (2) patients who had received sustained treatment for $\mathrm{OAB}$ for more than 3 months during the previous year, (3) patients experiencing acute urinary tract infection symptoms during the study period, (4) patients who were diagnosed or suspected of having interstitial cystitis, (5) patients who received urinary tract catheterization or were in the training process for intermittent self-catheterization, (6) patients for whom the use of anticholinergic agents was prohibited due to an overactive reaction, (7) patients with a severe liver disorder (glutamic oxaloacetic transaminase or glutamic pyruvic transaminase levels higher than $100 \mathrm{IU} / \mathrm{L}$ ) or renal failure (creatinine over $3 \mathrm{mg} / \mathrm{dL}$ ), (8) patients who received treatment for existing depression or for whom depression treatment was expected to be performed in parallel with $O A B$ treatment, (9) patients who had depressive symptoms unrelated to $\mathrm{OAB}$, and (10) patients who were determined to be unsuitable for clinical testing by the personnel in charge of administering the study. Based on these standards, solifenacin at a dose of $5 \mathrm{mg}$ in 1 tablet was administered to each participating patient with $\mathrm{OAB} 1$ time every day, and patients were instructed to answer various questionnaires to assess symptom improvement at the first visit, week 4, and week 12. Based on the Beck Depression Inventory (BDI) questionnaire, test subjects were divided into group 1, without depressive symptoms (0-9 points), and group 2, with depressive symptoms (10 or more points).

\section{Survey Questionnaire Urinary scales}

The OABSS, which is used to make a diagnosis by evaluating OAB symptoms [9]; the International Prostate Symptom Score-QoL (IPSS-QoL) score, which evaluates the severity of lower urinary tract symptoms (LUTS) [10]; and patient perception of bladder condition (PPBC) [11] were used to evaluate the outcomes.

\section{Depression scale}

The BDI questionnaire was used to measure the severity of depression. The BDI is a multiple-choice self-report inventory and is the tool most widely used to identify the level of depressive 
symptoms in an individual [12]. It has 21 questions and assesses an individual's feelings over the past week. Based on total BDI score, an individual's depressive symptom status is determined as follows: normal, $0-9$ points; mild, $10-15$ points; moderate, 16-23 points; and severe, 24 or more points [13].

\section{Statistical Analysis}

All the data were recorded and analyzed using standard forms. The Student $\mathrm{t}$-test was used to compare the results between the 2 groups. Between-group comparisons for continuous variables were performed using the parametric independent $t$-test. Statis- tical analysis was performed in IBM SPSS Statistics ver. 22.0 (IBM Co., Armonk, NY, USA), and P-values $<0.05$ were considered to indicate statistical significance.

\section{RESULTS}

A total of 72 patients participated in this clinical study, and 52 patients completed the study. Twenty patients were excluded: 13 due to loss to follow-up; 5 due to drug side effects related to constipation (2), xerostomia (2), and heartburn (1); 1 due to a hip joint operation; and 1 who voluntarily dropped out.

Table 1. Basic participant characteristics

\begin{tabular}{|c|c|c|c|c|}
\hline Characteristic & Total $(\mathrm{n}=52)$ & Group $1(n=21)$ & Group $2(n=31)$ & P-value \\
\hline Age (yr) & $61.22 \pm 11.19$ & $56.44 \pm 11.37$ & $64.0 \pm 10.26$ & 0.02 \\
\hline Height (cm) & $156.63 \pm 5.46$ & $159.06 \pm 5.27$ & $155.23 \pm 5.13$ & 0.02 \\
\hline Weight (kg) & $59.39 \pm 9.40$ & $60.33 \pm 11.79$ & $58.84 \pm 7.87$ & 0.60 \\
\hline $\mathrm{Qmax}(\mathrm{mL} / \mathrm{sec})$ & $22.10 \pm 11.07$ & $26.37 \pm 11.61$ & $19.62 \pm 10.11$ & 0.04 \\
\hline RU & $22.89 \pm 25.97$ & $22.26 \pm 26.94$ & $23.25 \pm 25.84$ & 0.90 \\
\hline OAB-Total & $9.02 \pm 3.29$ & $7.33 \pm 2.75$ & $10.16 \pm 3.17$ & $<0.01$ \\
\hline OAB No. $3^{\text {a) }}$ & $3.88 \pm 1.08$ & $3.29 \pm 1.01$ & $4.29 \pm 0.94$ & $<0.01$ \\
\hline IPSS1 & $2.29 \pm 1.79$ & $2.29 \pm 1.77$ & $2.29 \pm 1.83$ & 0.99 \\
\hline IPSS2 & $3.23 \pm 1.69$ & $2.90 \pm 1.73$ & $3.45 \pm 1.65$ & 0.25 \\
\hline IPSS3 & $1.17 \pm 1.41$ & $1.14 \pm 1.24$ & $1.19 \pm 1.54$ & 0.90 \\
\hline IPSS4 & $3.48 \pm 1.52$ & $3.00 \pm 1.30$ & $3.81 \pm 1.58$ & 0.59 \\
\hline IPSS5 & $1.88 \pm 1.72$ & $1.67 \pm 1.68$ & $2.03 \pm 1.76$ & 0.45 \\
\hline IPSS6 & $0.58 \pm 1.36$ & $0.29 \pm 1.10$ & $0.77 \pm 1.50$ & 0.20 \\
\hline IPSS7 & $2.52 \pm 1.54$ & $1.90 \pm 1.38$ & $2.94 \pm 1.53$ & 0.01 \\
\hline IPSS-Total & $15.10 \pm 7.09$ & $13.14 \pm 6.26$ & $16.42 \pm 7.41$ & 0.10 \\
\hline IPSS storage $^{\text {b) }}$ & $9.06 \pm 3.68$ & $7.81 \pm 3.19$ & $9.90 \pm 3.80$ & 0.04 \\
\hline IPSS voiding ${ }^{c)}$ & $4.87 \pm 0.68$ & $5.33 \pm 4.08$ & $6.55 \pm 5.35$ & 0.38 \\
\hline QoL & $4.62 \pm 1.01$ & $4.33 \pm 1.11$ & $4.81 \pm 0.91$ & 0.09 \\
\hline PPBC & $4.62 \pm 0.93$ & $4.29 \pm 0.78$ & $4.84 \pm 0.97$ & 0.03 \\
\hline BDI & $14.46 \pm 8.36$ & $6.62 \pm 1.56$ & $19.77 \pm 6.70$ & $<0.01$ \\
\hline Chronic disease & $14(26.9)$ & $8(38.1)$ & $6(19.4)$ & $<0.90$ \\
\hline Hypertension & $6(11.5)$ & $4(19.0)$ & $2(6.5)$ & \\
\hline Diabetes & $5(9.6)$ & $2(9.5)$ & $3(9.7)$ & \\
\hline Congestive heart failure & $1(1.9)$ & $1(4.8)$ & $0(0.0)$ & \\
\hline Asthma & $2(3.8)$ & $1(4.8)$ & $1(3.2)$ & \\
\hline
\end{tabular}

Values are presented as mean \pm standard deviation or number (\%).

Group 1, nondepressive symptom (0-9 points); group 2, depressive symptom (10 or more points); IPSS, International Prostate Symptom Score; $\mathrm{PPBC}$, patient perception of bladder condition; QoL, quality of life; OABSS, overactive bladder symptom score; BDI, Beck Depression Inventory; Qmax, maximum flow rate; RU, residual urine.

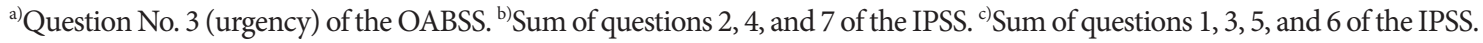




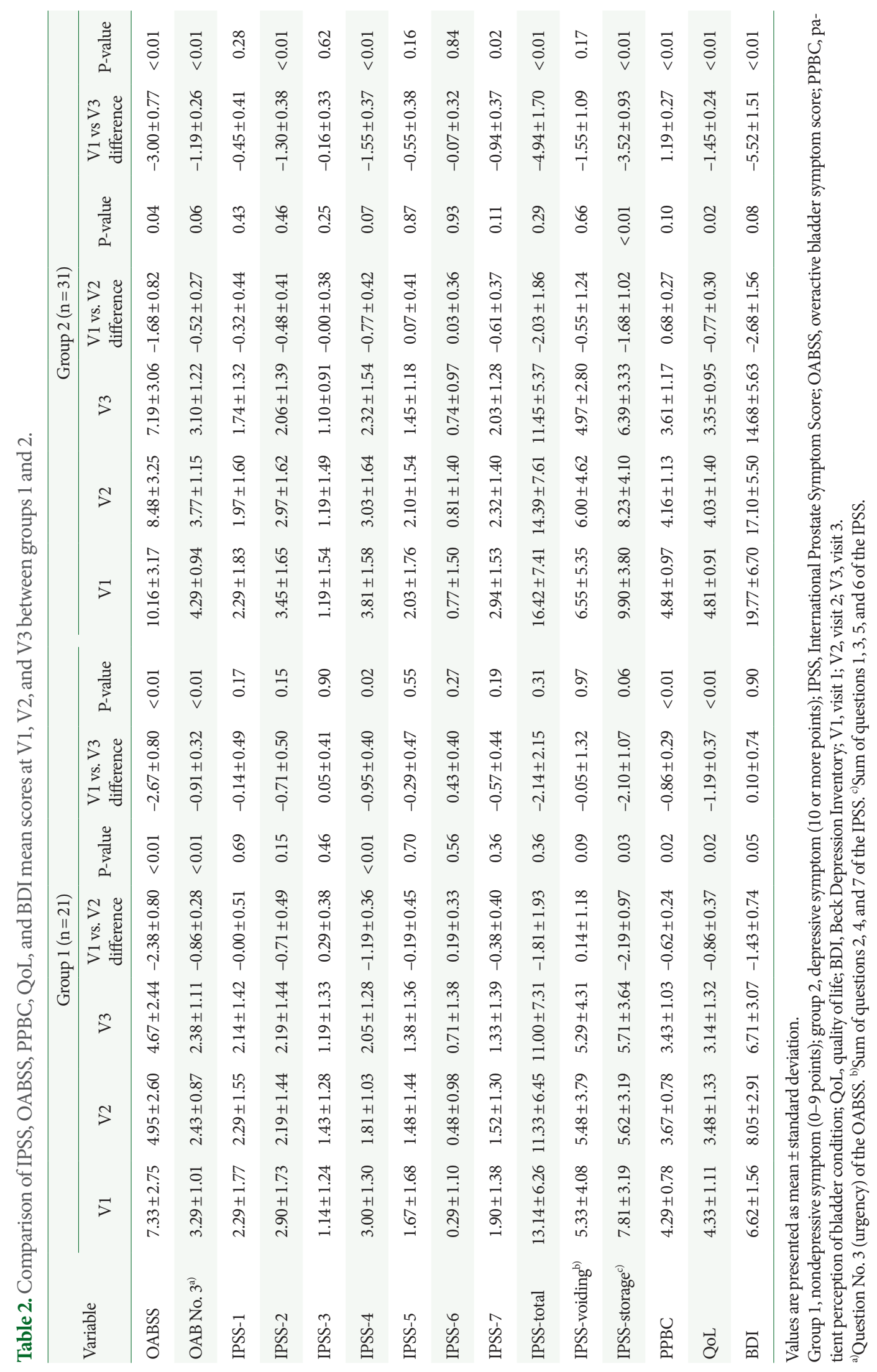


Table 3. Effect of treatment with Solifenacin at the fourth and 12th weeks in patients with overactive bladder with depressive symptoms

\begin{tabular}{|c|c|c|c|c|c|c|}
\hline \multirow{2}{*}{ Variable } & \multicolumn{3}{|c|}{ Change from baseline at week $4(n=21)$} & \multicolumn{3}{|c|}{ Change from baseline at week $12(\mathrm{n}=31)$} \\
\hline & Group 1 & Group 2 & P-value ${ }^{\mathrm{d})}$ & Group 1 & Group 2 & P-value ${ }^{\mathrm{d})}$ \\
\hline OABSS & $-2.38 \pm 2.56$ & $-1.68 \pm 3.33$ & 0.41 & $-2.67 \pm 2.74$ & $-2.97 \pm 2.95$ & 0.71 \\
\hline OAB No. $3^{\mathrm{a})}$ & $-0.86 \pm 1.01$ & $-0.52 \pm 1.18$ & 0.29 & $-0.90 \pm 1.18$ & $-1.19 \pm 0.79$ & 0.30 \\
\hline IPSS-total & $-1.81 \pm 4.25$ & $-2.03 \pm 5.62$ & 0.88 & $-2.14 \pm 5.69$ & $-4.97 \pm 6.84$ & 0.13 \\
\hline IPSS-voiding ${ }^{\mathrm{b})}$ & $0.14 \pm 2.31$ & $-0.55 \pm 3.44$ & 0.43 & $-0.05 \pm 3.54$ & $-1.58 \pm 4.86$ & 0.22 \\
\hline IPSS-storage $^{c}$ & $-2.19 \pm 2.77$ & $-1.68 \pm 3.63$ & 0.59 & $-2.10 \pm 3.53$ & $-3.52 \pm 3.68$ & 0.17 \\
\hline PPBC & $-0.62 \pm 0.74$ & $-0.68 \pm 0.68$ & 0.79 & $-0.86 \pm 0.79$ & $-1.23 \pm 0.76$ & 0.10 \\
\hline QoL & $-0.86 \pm 1.46$ & $-0.77 \pm 1.31$ & 0.83 & $-1.19 \pm 1.50$ & $-1.45 \pm 0.81$ & 0.42 \\
\hline BDI & $1.43 \pm 0.74$ & $-2.68 \pm 4.05$ & $<0.001$ & $0.10 \pm 3.37$ & $-5.52 \pm 5.82$ & $<0.001$ \\
\hline
\end{tabular}

Values are presented as mean \pm standard deviation.

Group 1, nondepressive symptom (0-9 points); group 2, depressive symptom (10 or more points); OABSS, overactive bladder symptom score; IPSS, International Prostate Symptom Score; PPBC, patient perception of bladder condition; QoL, quality of life; BDI, Beck Depression Inventory.

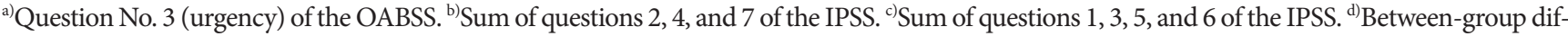
ferences in median percentage changes.

No significant differences were found in patients' basic characteristics, except for age and maximal urinary flow rate, or the average measurements of the patients. However, when comparing the total averages of the questionnaires in groups 1 and 2 , significant differences were found in OABSS-total $(7.33 \pm 2.75$ vs. $10.16 \pm 3.17, \mathrm{P}<0.01)$, OABSS Q3 ( $3.29 \pm 1.01$ vs. $4.29 \pm 0.94$, $\mathrm{P}<0.01)$, IPSS-total $(13.14 \pm 6.26$ vs. $16.42 \pm 7.41, \mathrm{P}=0.10)$, IPSS-storage (7.81 \pm 3.19 vs. $9.90 \pm 3.80, \mathrm{P}=0.04)$, and BDI (6.62 \pm 1.56 vs. $19.77 \pm 6.70, \mathrm{P}<0.01$ ), with the group showing depressive symptoms having higher values in each of these surveys (Table 1$)$. The OABSS results were categorized as mild (35), moderate (6-11), moderate, and severe (12 or more). Participants with severe OABSS scores showed significantly higher values for all question items, including BDI, PPBC, IPSS-voiding, IPSS-QoL, IPSS-storage, and OABSS. In participants with mild, moderate, and severe OABSS scores, the BDI values were $9.82 \pm 6.57,14.11 \pm 8.81$, and $18.79 \pm 6.85(\mathrm{P}<0.01)$, respectively, showing that higher OABSS scores were associated with more depressive symptoms.

Symptom improvement status and variation after solifenacin treatment for 12 weeks were compared in groups 1 and 2. During treatment with solifenacin, at weeks 4 and 12, most patients in both groups showed improvements in OABSS, PPBC, IPSS, IPSS-QoL, and BDI. In group 1, significant improvement was also noted for OABSS $(-2.67 \pm 0.80, \mathrm{P}<0.01)$, OABSS Q3 $(-0.91 \pm 0.32, \mathrm{P}<0.01), \mathrm{PPBC}(-0.86 \pm 0.29, \mathrm{P}<0.01)$, and IPSSQoL $(-0.86 \pm 0.37, \mathrm{P}<0.01)$. However, group 2 showed significantly greater improvement than group 1 for many items, includ- ing OABSS $(-3.00 \pm 0.77, \mathrm{P}<0.01)$, OABSS Q3 $(-1.19 \pm 0.26$, $\mathrm{P}<0.01)$, IPSS $-2(-1.30 \pm 0.38, \mathrm{P}<0.01)$, IPSS $-4(-1.55 \pm 0.37$, $\mathrm{P}<0.01)$, IPSS-total $(-4.94 \pm 1.70, \mathrm{P}<0.01)$, IPSS-storage $(-3.52 \pm .0 .93, \mathrm{P}<0.01)$, PPBC $(-1.19 \pm 0.27, \mathrm{P}<0.01)$, IPSS-QoL $(-1.45 \pm 0.24, \mathrm{P}<0.01)$, and BDI $(-5.52 \pm 1.51, \mathrm{P}<0.01)$ (Table 2$)$. Solifenacin was associated with statistically significant decreases in the BDI score from baseline to weeks 4 and 12 in group 2 in comparison to group 1 (group 1 vs. group 2: $1.43 \pm 0.74$ vs. $-2.68 \pm 4.05, \mathrm{P}<0.001$ at week $4 ; 0.10 \pm 3.37$ vs. $-5.52 \pm 5.82$, $\mathrm{P}<0.001$ at week 12). Additionally, the BDI showed statistically significant differences at weeks 4 and 12 in both groups (Table 3 ). This finding indicates that solifenacin simultaneously relieved OAB symptoms and improved depressive symptoms.

\section{DISCUSSION}

In this study, we observed improvements in depressive symptoms and $\mathrm{OAB}$ symptoms, as assessed by questionnaires, in participants taking solifenacin. The participants were grouped according to whether a patient with OAB had depressive symptoms. OAB symptoms and QoL were improved by solifenacin treatment. These results showed that solifenacin was effective not only for moderating $\mathrm{OAB}$ symptoms, but also for improving depressive symptoms caused by $\mathrm{OAB}$.

In the field of urology, urinary stone (calculus), incontinence, and LUTS are related with QoL and depression [14-16], and $\mathrm{OAB}$ also adversely affects QoL, including negative effects in areas such as emotional health, productivity at home or work, 
sociality, sexuality, and physical ability [17]. OAB sometimes creates problems not only with QoL, but also has neuropsychiatric ramifications (i.e., depression, uneasiness, poor sleep, decreased sexual relations, a sense of shame, impaired family relationships, etc.) [18]. Depression affects personal health, family, and economic life and is associated with conditions such as diabetes, asthma, arthritis, and chronic obstructive disease [19]. According to the US National Institute of Mental Health, the lifetime incidence rate of depression is $16.5 \%$, and it is forecasted to be the second most prevalent disease by 2020 [20]. Depression is a mental health problem frequently associated with decreased QoL in OAB patients. According to a previous study, $\mathrm{OAB}$ interferes with daily life, resulting in weight gain due to an inability to exercise and avoidance of social situations. Sleep disturbance caused by anxiety and nocturia, fatigue, and exhaustion in daily life have been proposed to induce depression [21]. In the study performed by Anger et al. [22], a guilty conscience was also found in $\mathrm{OAB}$ patients. It is highly likely that the occurrence of a guilty conscience may lead to depression. In this way, $\mathrm{OAB}$ and depression are closely related, and this relationship has been reported in several studies. The Epidemiology of Lower Urinary Tract Symptoms (EpiLUTS) study indicated that in patients with OAB symptoms, QoL was markedly lower, and anxiety and depression were higher [23]. A study performed in Korea reported that in patients with $\mathrm{OAB}$, the depression rate was $39.3 \%$ [24]. In a study of the QoL of OAB patients, patients expressed constant worry about searching for and reaching a toilet in time to prevent urine leakage. For some patients, anxiety about constantly needing to go to the toilet created feelings of hopelessness and depression. Feelings of depression were also caused by nocturia, which interrupts sleep at night, resulting in exhaustion and fatigue and causing social isolation due to the avoidance of social situations [21]. OAB symptoms can lead to depressive symptoms, and related secondary behaviors have been found to contribute to depressive symptoms. In our study, the severity of $\mathrm{OAB}$ symptoms was directly related to more serious depressive symptoms, but we must also consider the effects of secondary behaviors. Depression and OAB are closely connected; however, information about whether depression improves as a result of treating $\mathrm{OAB}$ is not available.

In the EpiLUTS survey, the percentage of patients managing $\mathrm{OAB}$ symptoms with coping behaviors exceeded the percentage treated with medication. This finding indicates that some patients may prefer to self-manage OAB symptoms, and possibly that patients do not discuss their symptoms with their physi- cian [23]. Self-controlling OAB symptoms may lead to a low QoL and cause depressive symptoms. Diagnosing $\mathrm{OAB}$ is very important, and treatment of $\mathrm{OAB}$ is needed to improve $\mathrm{OAB}$ symptoms and to prevent secondary problems such as anxiety and depression.

The treatment of $\mathrm{OAB}$ mainly involves anticholinergic agents, which are frequently used for patients with detrusor overactivity confirmed by a urodynamic study or only by symptoms [25]. Antimuscarinic agents play a significant role in improving the QoL of patients affected by OAB [26]. In some studies, compliance with these drugs was found to be relatively low for the treatment of $\mathrm{OAB}$ in spite of the excellent effectiveness of antimuscarinic agents, possibly due to the side effects of xerostomia, constipation, and blurred eyesight [27]. However, in cases where efficacy is excellent without any side effects, the satisfaction of the patients was relatively favorable.

A pilot study demonstrated improvement in depressive symptoms when LUTS patients were administered tamsulosin to treat concomitant benign prostatic hyperplasia. In that study, it was observed that after administering tamsulosin to patients with LUTS-associated depression, both LUTS and depression improved [28]. In the current study, during treatment with solifenacin in patients with $\mathrm{OAB}$, not only were $\mathrm{OAB}$ symptoms alleviated, but QoL and depressive symptoms improved simultaneously. A limitation of this study was the small number of study participants and the fact that groups 1 and 2 differed with regard to certain basic characteristics. To clarify the relationship between pharmacological treatment for $\mathrm{OAB}$ and depression, a large-scale, random, blinded study will be required in the future.

Since OAB is very relevant for mental health-related conditions such as depression, QoL, and anxiety disorders, it will be necessary to elucidate the pathophysiology of OAB in detail and then to select customized therapeutic methods.

In conclusion, $\mathrm{OAB}$ symptoms reduced patients' QoL and were associated with depressive symptoms. In OAB accompanied by depressive symptoms, administering solifenacin to alleviate $\mathrm{OAB}$ symptoms simultaneously improved QoL and depressive symptoms.

\section{REFERENCES}

1. Wein AJ. Diagnosis and treatment of the overactive bladder. Urology 2003;62(5 Suppl 2):20-7.

2. Coyne KS, Sexton CC, Vats V, Thompson C, Kopp ZS, Milsom I. National community prevalence of overactive bladder in the Unit- 
ed States stratified by sex and age. Urology 2011;77:1081-7.

3. Ganz ML, Smalarz AM, Krupski TL, Anger JT, Hu JC, WittrupJensen KU, et al. Economic costs of overactive bladder in the United States. Urology 2010;75:526-32, 532.e1-18.

4. Liberman JN, Hunt TL, Stewart WF, Wein A, Zhou Z, Herzog AR, et al. Health-related quality of life among adults with symptoms of overactive bladder: results from a U.S. community-based survey. Urology 2001;57:1044-50.

5. Coyne KS, Sexton CC, Irwin DE, Kopp ZS, Kelleher CJ, Milsom I. The impact of overactive bladder, incontinence and other lower urinary tract symptoms on quality of life, work productivity, sexuality and emotional well-being in men and women: results from the EPIC study. BJU Int 2008;101:1388-95.

6. Lee KS, Lee HW, Choo MS, Paick JS, Lee JG, Seo JT, et al. Urinary urgency outcomes after propiverine treatment for an overactive bladder: the 'Propiverine study on overactive bladder including urgency data'. BJU Int 2010;105:1565-70.

7. D'Souza AO, Smith MJ, Miller LA, Doyle J, Ariely R. Persistence, adherence, and switch rates among extended-release and immediate-release overactive bladder medications in a regional managed care plan. J Manag Care Pharm 2008;14:291-301.

8. Kessler RC, Berglund P, Demler O, Jin R, Merikangas KR, Walters EE. Lifetime prevalence and age-of-onset distributions of DSM-IV disorders in the National Comorbidity Survey Replication. Arch Gen Psychiatry 2005;62:593-602.

9. Dmochowski RR, Rosenberg MT, Zinner NR, Staskin DR, Sand PK. Extended-release trospium chloride improves quality of life in overactive bladder. Value Health 2010;13:251-7.

10. Choi HR, Chung WS, Shim BS, Kwon SW, Hong SJ, Chung BH, et al. Translation Validity and Reliability of I-PSS Korean Version. Korean J Urol 1996;37:659-65.

11. Rogers RG, Bachmann G, Scarpero H, Jumadilova Z, Sun F, Morrow JD, et al. Effects of tolterodine ER on patient-reported outcomes in sexually active women with overactive bladder and urgency urinary incontinence. Curr Med Res Opin 2009;25:2159-65.

12. Beck AT, Ward CH, Mendelson M, Mock J, Erbaugh J. An inventory for measuring depression. Arch Gen Psychiatry 1961;4:561-71.

13. Kendall PC, Hollon SD, Beck AT, Hammen CL, Ingram RE. Issues and recommendations regarding use of the Beck Depression Inventory. Cogn Ther Res 1987;11:289-99.

14. Miranda Ede P, Gomes CM, Torricelli FC, de Bessa J Júnior, de Castro JE, Ferreira BR, et al. Nocturia is the lower urinary tract symptom with greatest impact on quality of life of men from a community setting. Int Neurourol J 2014;18:86-90.

15. Melville JL, Fan MY, Rau H, Nygaard IE, Katon WJ. Major depres- sion and urinary incontinence in women: temporal associations in an epidemiologic sample. Am J Obstet Gynecol 2009;201:490.e1-7.

16. Angell J, Bryant M, Tu H, Goodman M, Pattaras J, Ogan K. Association of depression and urolithiasis. Urology 2012;79:518-25.

17. Chiaffarino F, Parazzini F, Lavezzari M, Giambanco V; Gruppo Interdisciplinare di Studio Incontinenza Urinaria (GISIU). Impact of urinary incontinence and overactive bladder on quality of life. Eur Urol 2003;43:535-8.

18. Irwin DE, Milsom I, Kopp Z, Abrams P, Cardozo L. Impact of overactive bladder symptoms on employment, social interactions and emotional well-being in six European countries. BJU Int 2006;97:96-100.

19. Moussavi S, Chatterji S, Verdes E, Tandon A, Patel V, Ustun B. Depression, chronic diseases, and decrements in health: results from the World Health Surveys. Lancet 2007;370:851-8.

20. Brown P. The global burden of disease: summary. Boston: Harvard School of Public Health; 1996.

21. Nicolson P, Kopp Z, Chapple CR, Kelleher C. It's just the worry about not being able to control it! A qualitative study of living with overactive bladder. Br J Health Psychol 2008;13(Pt 2):343-59.

22. Anger JT, Nissim HA, Le TX, Smith AL, Lee U, Sarkisian C, et al. Women's experience with severe overactive bladder symptoms and treatment: insight revealed from patient focus groups. Neurourol Urodyn 2011;30:1295-9.

23. Milsom I, Kaplan SA, Coyne KS, Sexton CC, Kopp ZS. Effect of bothersome overactive bladder symptoms on health-related quality of life, anxiety, depression, and treatment seeking in the United States: results from EpiLUTS. Urology 2012;80:90-6.

24. Yoo ES, Kim BS, Kim DY, Oh SJ, Kim JC. The impact of overactive bladder on health-related quality of life, sexual life and psychological health in Korea. Int Neurourol J 2011;15:143-51.

25. Andersson KE. Antimuscarinics for treatment of overactive bladder. Lancet Neurol 2004;3:46-53.

26. Khullar V, Chapple C, Gabriel Z, Dooley JA. The effects of antimuscarinics on health-related quality of life in overactive bladder: a systematic review and meta-analysis. Urology 2006;68(2 Suppl):38-48.

27. Choo MS, Lee JZ, Lee JB, Kim YH, Jung HC, Lee KS, et al. Efficacy and safety of solifenacin succinate in Korean patients with overactive bladder: a randomised, prospective, double-blind, multicentre study. Int J Clin Pract 2008;62:1675-83.

28. Kim KS, Jang EY, Kim YT, Moon HS. Tamsulosin treatment affecting patient-reported outcomes in benign prostatic hyperplasia-associated depressive symptoms. Urology 2016;87:172-7. 